\title{
Carcinoma of the penis in a HIV positive patient
}

\author{
K Yoganathan, R N Patel, N Maitland, T J McManus, F M B Calman, A Pozniak
}

\section{Introduction}

Although squamous cell ano-rectal carcinomas have been increasingly recognised in immunosuppressed HIV infected men, this is, to our knowledge, the first reported case of squamous cell carcinoma of the penis in a HIV infected man.

\section{Case history}

In September 1985, a 37-year-old Caucasian homosexual man presented with perianal warts and was found to be HIV-1 antibody positive. He was a non-smoker and drank less than ten units of alcohol a week. Apart from an episode of perianal herpes in September 1987 he remained well. In June 1988, because his CD4 lymphocyte count was less than $200 / \mathrm{mm},{ }^{3}$ he was commenced on zidovudine $1000 \mathrm{mg}$ daily (reduced to $500 \mathrm{mg}$ daily 20 months later) and aerosol pentamidine. In June 1990 when the CD4 lymphocyte count was 20 cells $/ \mathrm{mm}^{3}$ he developed an episode of bronchoscopically confirmed Pneumocystis carinii pneumonia thought to be as a result of poor compliance with aerosol pentamidine. He responded to standard high-dose co-trimoxazole therapy. He went on to develop recurrent oral candidiasis and eosinophilis folliculitis.

In May 1992 he presented with a six month history of penile ulceration. He was uncircumcised and had a polypoid $1.5 \mathrm{~cm} \times 1.5 \mathrm{~cm}$ lesion in the coronal sulcus and bilateral painless rubbery lymphadenopathy. $\mathrm{He}$ had a CD4 lymphocyte count of less than 20 cells $/ \mathrm{mm}^{3}$ and was P24 antigen positive. Culture for herpes simplex virus (HSV) was negative and his syphilis serology was negative. Serum calcium, phosphate, liver function tests, urea and electrolytes were all within normal limits. He was referred to a urologist who excised the lesion completely. The histology of the lesion showed carcinoma in situ with moderate dysplasia and koilocytosis. There was no evidence of invasion. The scar healed completely.

The biopsy was positive for Human papillomavirus (HPV) 16 by PCR using HPV 16 specific primers which amplify a DNA fragment of 352 base pairs. ${ }^{1}$

In November 1992 the penile ulcer recurred at the same site and rapidly enlarged. There was a $1 \mathrm{~cm}$ diameter indurated ulcer with raised rolled edges extending to the coronal sulcus. A repeat biopsy showed well differentiated squamous cell carcinoma and inguinal node biopsies showed no evidence of metastasis. He was circumcised and then underwent treatment with radiotherapy.

$\mathrm{He}$ was treated with cobalt60 gamma rays $100 \mathrm{~cm}$ fsd using a standardised wax block and a parallel opposed pair of fields, receiving 55 Grays in 22 fractions in 35 days, with a one week rest after 42 Grays because of severe mucositis. The groin nodes were not treated electively.

Following radiotherapy the mucositis was slow to heal and was not complete until three months after completion of treatment. Initially admission was required for dressings and analgesia but latterly the dressings were managed on an out-patient basis. Healing was unfortunately further delayed by a biopsy of the granulating area six weeks after radiotherapy which confirmed granulation tissue only.

\section{Discussion}

Carcinoma of the penis is a rare neoplasm, accounting for only $0.4 \%$ to $0.6 \%$ of all male malignancies in Europe and North America. It usually presents in the sixth decade of life and is uncommon in men of less than 40 years of age. The precise aetiology of penile carcinoma remains undetermined but epidemiological data suggest an increasing role of $\mathrm{HPV}^{234}$ and association with lack of circumcision. ${ }^{5}$ Our patient had a clinical evidence of perianal warts and histological evidence of penile HPV infection. HPV, particularly types 16 and 18, has been associated with cervical neoplasia, invasive squamous carcinoma of the penis ${ }^{2}$ and ano-rectal dysplasia. ${ }^{6}$

The development of carcinoma in association with immunosuppression is being increasingly recognised. This patient was severely immunosuppressed with a CD4 count of less than $100 / \mathrm{mm}^{3}$ for nearly five years and had been on high doses of zidovudine for 20 months. Although in the rat model high doses of zidovudine is known to cause vaginal neoplasia the effect of long-term zidovudine is not yet known in terms of carcinogenesis in humans.

Human herpes simplex virus has been suspected as being involved in the aetiology of cancer, like Epstein-Barr virus in Burkitt's lymphoma and nasopharyngeal cancer. ${ }^{7}$ Exophytic squamous epithelial proliferations characteristic of condylomata contain HPV types 6 and 11 . In contrast, invasive squamous carcinomas of the genital area often contain evidence of HPV types 16, 18, 31 and 


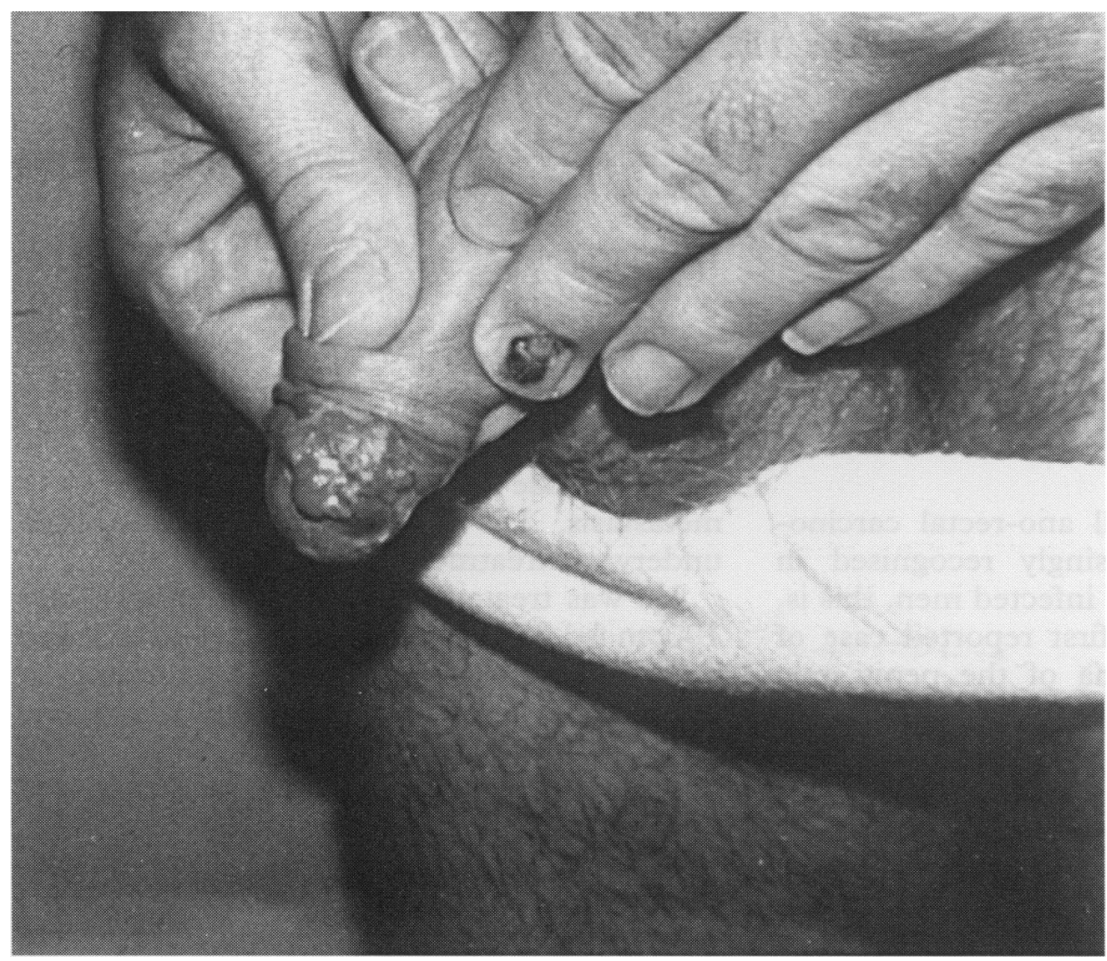

Figure 1 showing polypoid, ulcerated growth in the coronal sulcus.

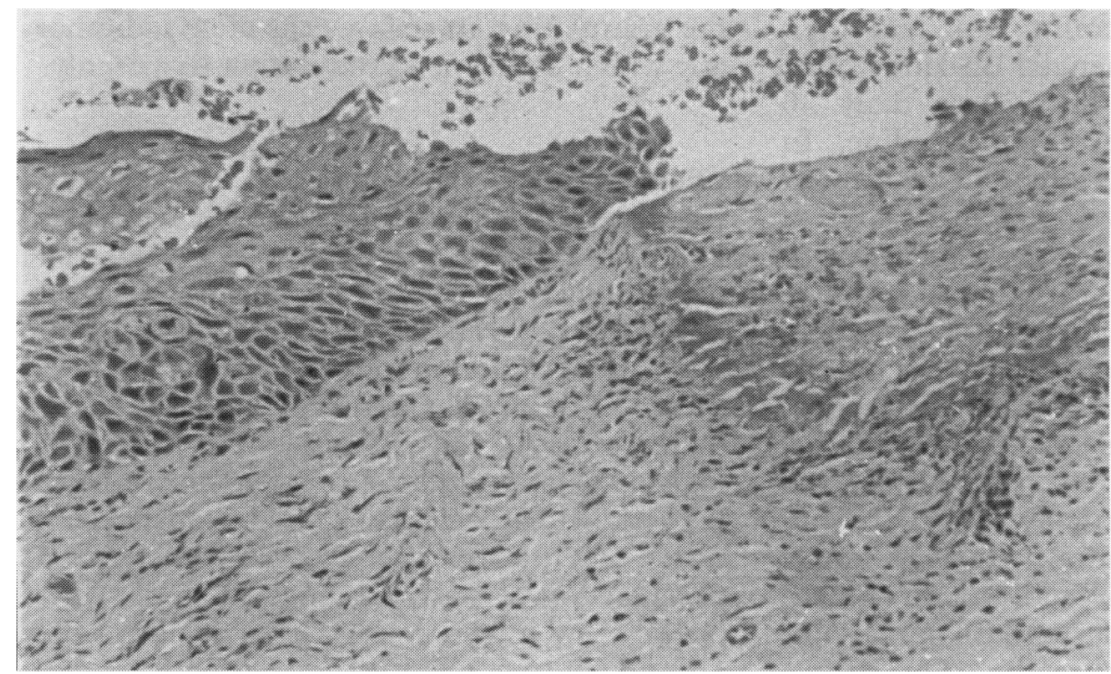

Figure 2 showing carcinoma in situ with moderate dysplasia and koilocytosis.

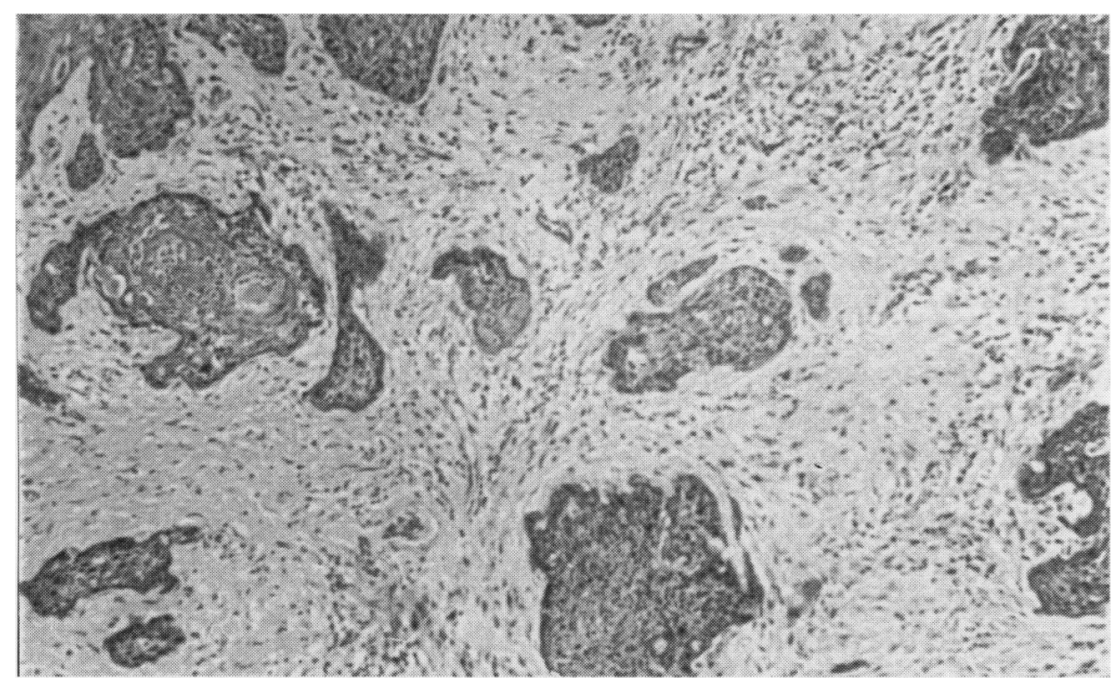

Figure 3 showing well-differentiated keratinised squamous cell carcinoma.
$33^{8}$ and the frequency of this finding is dependent on the type of test performed. In this case HPV 16 was positive by using PCR technique but we have not ruled out the possibility of multiple HPV infections being present in this case as only one HPV type was looked for.

The most important prognostic factor for carcinoma of the penis is the stage at presentation. ${ }^{910}$ This patient presented early with a $\mathrm{T} 1$ No carcinoma of the glans, just extending to the coronal sulcus. Radiotherapy gives local control rates in excess of $80 \%$ in early carcinoma of the penis with a disease specific five year survival of $70 \% .^{10}$ The unusually severe normal tissue reaction to radiotherapy exhibited by HIV positive patients is well recognised, ${ }^{11}$ but where radical curative treatment is being undertaken, it is not possible to modify the total radiation dose for fear of compromising the chances of local control. It is normally advised that the fraction size should on be kept as low as possible to minimise the local reaction and late sequelae of radiotherapy. ${ }^{3}$ The tumour has remained controlled $15 \pm$ months following treatment. Our patient's prognosis probably depends on the fact that he is likely to develop other life-threatening diseases as a result of his immunosuppression.

As the HIV epidemic continues to evolve, clinicians may well be faced with the management of uncommon malignancies. A high index of suspicion and early biopsy are crucial in the management of penile malignancies.

We thank Dr P O'Donnell for preparing the histology slides. The authors also thank Catriona Talbot for typing the manuscript.

1 Jalal H, Sanders CM, Prime SS, Scully C, Maitland NJ. Detection of human papilloma virus type $16 \mathrm{DNA}$ in oral squames from normal young adults. F Oral Pathol Med 1992;21:465-70.

2 Sarkar FH, Miles BJ, Plieth DH, Crissman JC. Detection of Human papillomavirus in squamous neoplasms of the penis, F Urol 1992;147:389-92.

3 Campion MJ, McCance DJ, Mitchell HS, Jenkins D and Singer A. Subclinical penile human papillomavirus infection and dysplasia in consorts of women with cervical neoplasia. Genitourin Med. 1988;64:90-9.

4 Tabrizi SN, Ta J, Quinn M, Borg AJ, Garland SM. Genitourin Med. 1992;68:370-3.

5 Burgess JK, Badalment RA, Drago JR. Penile cancer: clinical presentation, diagnosis and staging. Urol Clin North Am 1992;68:247-56.

6 Frazer IH, Crapper RM, Medley G, Brown TC, Mackay IR. Association between ano-rectal dysplasia, Human papilloma virus and Human immunodeficiency virus infection in homosexual men. Lancet 1986;i:657-60.

7 Mott Prize CS. Papilloma viruses in human cancer Cancer 1987;59:1692-6.

8 Higgins GD, Uzelin DM, Phillips GD, Villa LL, Burrell CJ. Differing prevalence of Human papillomavirus RNA in penile dysplasias and carcinomas may reflect differing etiologies. Am f Clin Pathol 1992;97:272-8.

9 Fernando JJR, Wanas TM. Squamous carcinoma of the penis and previous recurrent balanitis: a case report. Genitourin Med 1991;67:153-5.

10 Duncan W, Jackson SM. The treatment of early cancer of the penis with megavoltage $\mathrm{x}$-rays. Clin Radiol 1972;23: 246.

11 Le Bourgeois JP, Frikha $H$, Piedbois P, Le Pechoux C, Martin L, Haddad H. Radiotherapy in the management of epidemis Kaposi's sarcoma of the oral cavity, the eyelid and the genitals. Radiother Oncol 1994;30:263-6. (1)

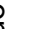

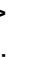

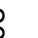

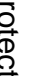
.

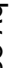
$\frac{100}{20}$ 